\title{
Prevalence of Metabolic Syndrome Among Adults (20 to 40 Years of Age) in Coimbatore
}

\author{
K. Kavitha ${ }^{1, \text { * }}$, K. Anusuya Devi ${ }^{2}$ \\ ${ }^{1}$ Dept of Food and Nutrition, P S G College of Arts and Science, Coimbatore, Tamil Nadu, India \\ ${ }^{2}$ Dept of Clinical Nutrition and Dietetics, P S G College of Arts and Science, Coimbatore, Tamil Nadu, India
}

Email address:

kavithasureshphd@gmail.com (K. Kavitha), anusuyavimal@gmail.com (K. A. Devi)

\section{To cite this article:}

K. Kavitha, K. Anusuya Devi. Prevalence of Metabolic Syndrome Among Adults (20 to 40 Years of Age) in Coimbatore. International Journal of Nutrition and Food Sciences. Vol. 4, No. 1, 2015, pp. 66-68. doi: 10.11648/j.ijnfs.20150401.19

\begin{abstract}
The metabolic syndrome has acknowledged a primary attention in the last few years. It is defined as a cluster of specific cardiovascular disease (CVD) risk factors, comprised of central obesity, elevated blood pressure, high triglycerides, reduced levels of high-density lipoprotein (HDL) cholesterol and elevated fasting glucose levels. Several studies have identified that there is a significant association of Metabolic Syndrome with pancreatic, colorectal, breast and prostatic cancer. Most of the cities in India are also undergoing rapid urbanization with increased industrialization and there by facing an unhealthy diet, physical inactivity and adoption of other unhealthy lifestyles which leads to rise in prevalence of non communicable diseases. Lot of work is being done on metabolic syndrome in the recent times but most of them have been confined to hospitals and very few studies have been conducted at community level. Therefore this study was conducted to assess the prevalence of metabolic syndrome in the adult population of Coimbatore City which is an important industrial hub of Tamilnadu. 992 persons participated in the survey and 300 samples with increased waist circumference were selected for Anthropometric measurement \& physiological indices. This study has revealed that the people with increased Waist Circumference (Central Obesity) are in the metabolic syndrome zone with the result of $83 \%$ of the obese samples are with Metabolic syndrome. This study also revealed that around $47 \%$ are in metabolic syndrome zone with the presence of 3 components and they could be in out of metabolic syndrome zone very easily just by reducing only one component. Though $17.66 \%$ of the persons are out of metabolic syndrome zone, $16.66 \%$ have 2 components and the probability to enter in to the metabolic syndrome zone is very high for them as they have central obesity which may leads to pre diabetics easily if they don't take at most care.
\end{abstract}

Keywords: Metabolic Syndrome, Prevalence, Adults

\section{Introduction}

There were no hazardous health issues during olden days when human used only his legs to move from one place to another, his hand to pick and carry any product, used swimming as a tool to cross any water body and ate fresh vegetable/fruits as food without cooking them. While all the above things were followed, metabolic activities in our body were happening properly and there by people lived for $100+$ years without much health issues. When science and technology started growing, we found vehicles to ease our transport, machineries for doing all heavy works and various food items just for taste etc. Our physical activity started reducing and a habit of consuming unhealthy food items just for taste started increasing. Metabolic activity of our body started getting disturbed due to our change in lifestyle and food habit. If any process is not happening as planned then a problem will definitely get created. In the same way problems stared in our body as the metabolic activity got disturbed in our body. When metabolic activity is not proper in our body, the consumed starch is stored as fat in the body and we became obese. We gained more cholesterol in blood due to improper food habits. This cholesterol and obesity started crating all other health issues like heart problems, diabetics etc. Hence these health issues are termed as Metabolic Syndrome. Metabolic syndrome is a growing problem among world population in this decade. Number of deaths due to cardio vascular disease, diabetes, obesity and even stress is increased worldwide and all these are the components of metabolic syndrome. The prevalence of the metabolic syndrome in the 
adult population of United States was estimated to be more than $25 \%$. Similarly, the prevalence of metabolic syndrome in 7 European countries was approximately 23\%. It was also estimated that $20 \%-25 \%$ of South Asians have developed metabolic syndrome and many more are expected to join it [1, 2]. Asian Indians are considered to be a "high-risk population" for both metabolic syndrome and Cardio Vascular Disease, which has instigated a number of studies $[3,4]$.

\section{Objective}

This study aimed to identify the prevalence rate of metabolic syndrome among adults aged between 20 years and 40 years with increased waist circumference residing in Coimbatore an important industrial hub of Tamil Nadu.

\section{Methods}

Sample size of 992 adults $\{$ Male $=523$ (52.7\%), Female $=$ $469(47.3 \%)\}$ who are $48 \%$ in job, $38 \%$ in Profession and $14 \%$ Home makers, in the prescribed age group was selected through random sampling. Anthropometric measurement \& physiological indices were carried out for all samples. According to NCEP ATP III criteria of Metabolic Syndrome, the participants with waist circumference $(\mathrm{N}=300)>40$ inches for Male $(\mathrm{N}=150) \&>35$ inches for Female $(\mathrm{N}=150)$ were selected for the biochemical profiling of TGL, HDL \& Fasting Glucose. Ethical permission obtained from the research ethics committee of PSGCAS (P S G College of Art and Science, Coimbatore, Tamilnadu, India.

NCEP ATP III Criteria:

Any 3 or more criteria from the below will be considered as Metabolic Syndrome.

- Central obesity (defined as waist circumference $\geq 90 \mathrm{~cm}$ for men and $\geq 80 \mathrm{~cm}$ for women)

- Raised TG level: $\geq 150 \mathrm{mg} / \mathrm{dL}$.

- Reduced HDL cholesterol: < $40 \mathrm{mg} / \mathrm{dL}$ in males and < $50 \mathrm{mg} / \mathrm{dL}$ in females.

- Raised blood pressure: systolic $\mathrm{BP} \geq 130$ or diastolic $\mathrm{BP} \geq$ $85 \mathrm{~mm} \mathrm{Hg}$.

- Raised fasting plasma glucose (FPG) $\geq 100 \mathrm{mg} / \mathrm{dL}$.

\section{Results and Discussions}

The mean age was $31.35 \pm 5.72 \mathrm{yrs}$, mean height was $165 \pm$ $5.75 \mathrm{cms}$, mean weight was $74.05 \pm 6.36 \mathrm{kgs}$, mean $\mathrm{WC}$ in men was $43.73 \pm 1.96$ inches, mean WC in women was 38.58 \pm 1.86 inches, mean Systolic BP was $125.03 \pm 13.24 \mathrm{mmHg}$, mean Diastolic Bp was $84 \pm 9.6 \mathrm{mmHg}$, mean HDL is $34 \pm 7.4$ $\mathrm{mg} / \mathrm{dl}$, mean TGL was $116.2 \pm 37.37 \mathrm{mg} / \mathrm{dl}$, and FBG mean is $102 \pm 14 \mathrm{mg} / \mathrm{dl}$.

Study revealed that 247 samples have metabolic syndrome among the 300 samples with increased waist circumference (Male 125/150 \& Female 122/150) with more than or equal to 3 criteria. All the 300 samples have Obesity, 141 have pre hypertension, 169 have pre diabetics, 282 have lower HDL levels and 73 have higher TGL levels.
The Joint National Committee (JNC) VII introduced the term "prehypertension," which is defined as BP levels of 120-139 $\mathrm{mmHg}$ for systolic and $80-89 \mathrm{mmHg}$ for diastolic BP, respectively (5). Pre-diabetes is an intermediate state of altered glucose metabolism with a heightened risk of developing type 2 diabetes and other associated complications. (6)



Chart 1. Prevalence \% of MS Components.

Among the 300 samples with increased waist circumference, all of them have Central Obesity. $49 \%$ of Female and $45 \%$ of Male have Pre Hypertension, $51 \%$ of Female and $62 \%$ of Male have Pre Diabetics, 95\% Female and $93 \%$ Male have Lower HDL Levels and $25 \%$ of Female and $24 \%$ of Male have Higher TGL Levels. It is to be noted that when Female contributes more in pre hyper tension, lower HDL level and higher TGL level with marginal difference of $4 \%, 2 \%$ and $1 \%$, Male leads with significant difference in Pre Diabetics which is $11 \%$. This revealed that Pre diabetic is higher in male when compared to female among those with increased waist circumference.

The study also revealed that among the 300 persons with increased waist circumference, $94 \%$ of them have lower HDL levels, $56 \%$ of them have pre diabetics, $47 \%$ of them have hypertension and $24 \%$ of them have higher TGL levels.

Table 1. Breakup of MS Components for prevalence.

\begin{tabular}{llll}
\hline Components & Male & Female & Total \\
\hline WC+PHT+P Dia & $4.00 \%$ & $2.67 \%$ & $3.33 \%$ \\
WC+PHT+L HDL & $11.33 \%$ & $16.00 \%$ & $13.67 \%$ \\
WC+P dia+L HDL & $22.00 \%$ & $17.33 \%$ & $19.67 \%$ \\
WC+L HDL+H TGL & $10.00 \%$ & $11.33 \%$ & $10.67 \%$ \\
Total & $47.33 \%$ & $47.33 \%$ & $47.33 \%$ \\
WC+PHT+P Dia+L HDL & $22.00 \%$ & $21.33 \%$ & $21.67 \%$ \\
WC+PHT+P Dia+H TGL & $1.33 \%$ & $0.67 \%$ & $1.00 \%$ \\
WC+PHT+L HDL+H TGL & $0.67 \%$ & $3.33 \%$ & $2.00 \%$ \\
WC+P Dia+L HDL+H TGL & $6.00 \%$ & $4.00 \%$ & $5.00 \%$ \\
Total & $30.00 \%$ & $29.33 \%$ & $29.67 \%$ \\
All 5 Components & $6.00 \%$ & $4.67 \%$ & $5.33 \%$ \\
\hline
\end{tabular}

WC - Increased Waist Circumference / Central Obesity, PHT - Pre Hypertension, P Dia - Pre Diabetics, H TGL - Higher TGL Level, L HDL Lower HDL Levels

Study also revealed that $47.33 \%$ of the 300 samples were 
falling under MS with the presence of 3 of its components with the following break up.

People with WC, Pre diabetics and Lower HDL levels leads with the contribution of $19.67 \%$, People with WC, Pre hypertension and Lower HDL level contributes 13.67\%, People with WC, Lower HDL levels and Higher TGL Levels contributes $10.67 \%$ and People with WC, Pre hypertension and Pre diabetics contributes $3.33 \%$. All these $47.33 \%$ of people can easily opt out from Metabolic Syndrome just by reducing the Waist circumference in common or any one component from their list.

There were $29.67 \%$ of persons falling under MS with the presence of 4 of its components with the below break up.

People with WC, Pre Hypertension, Pre diabetics and Lower HDL levels leads with the contribution of $21.67 \%$, People with WC, Pre diabetics, Lower HDL levels and Higher TGL levels contributes 5\%, People with WC, Pre Hypertension, Lower HDL levels and Higher TGL levels contributes $2 \%$, and People with WC, Pre Hypertension, Pre diabetics and Higher TGL levels contributes 1\%.

There were $5.33 \%$ falling under MS with the presence of all its components.

\section{People without MS prevalense among 300 samles with increased WC}

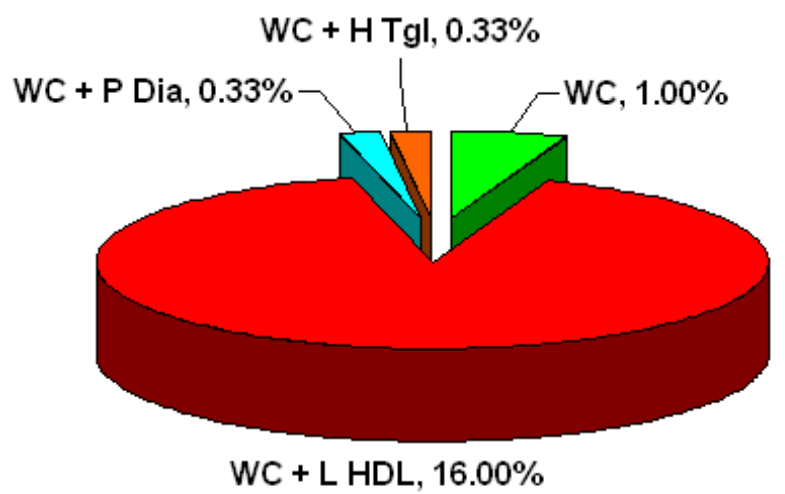

$\square W C \square W C+L H D L \square W C+P D i a \quad \square W C+H T g l$

Chart 2. People without MS

Study also revealed that $16 \%$ of the people have increased waist circumference and lower HDL levels, $0.33 \%$ have increased waist circumference and higher TGL levels and $0.33 \%$ have increased waist circumference and pre diabetics. So these $16.66 \%$ of the people with 2 components of metabolic syndrome were out of the prevalence, But they have huge probability of entering in to as they have increased waist circumference which can easily gift them pre diabetics or pre hyper tension. It is essential for these people to reduce the waist circumference to keep them out of metabolic syndrome.

Only $1 \%$ of the 300 persons have no other component other than the increased waist circumference. If these persons can reduce the waist circumference, they can reduce the probability to get in to metabolic syndrome.

\section{Conclusion}

The study revealed that among the 300 participants with increased WC, Prevalence rate of metabolic syndrome was $82.33 \% \quad(\mathrm{~N}=247)$ which comprises of $83.33 \%$ in men $(\mathrm{N}=125 / 150)$ and $81.33 \%$ in women $(\mathrm{N}=122 / 150)$. Further studies may be conducted on the impact of lifestyle changes on the prevalence of metabolic syndrome.

\section{Acknowledgement}

We sincerely thank all the participants in the study for their co operation and support.

\section{References}

[1] P. Nestel, R. Lyu, P. L. Lip et al., "Metabolic syndrome: recent prevalence in East and Southeast Asian populations," Asia Pacific Journal of Clinical Nutrition, vol. 16, no. 2, pp. 362-367, 2007.

[2] D. Eapen, G. L. Kalra, N. Merchant, A. Arora, and B. V. Khan, "Metabolic syndrome and cardiovascular disease in South Asians," Vascular Health and Risk Management, vol. 5, pp. 731-743, 2009.

[3] Ramachandran A, Satyavani K, Snehalatha C, et al. Clustering of Cardiovascular risk factors in urban Asian Indians. Diabetes Care. 1998; 21:967-71.

[4] Misra A, Wasir JS, Pandey RM. An Evaluation of candidate definitions of the Metabolic syndrome in adult Asian Indians. Diabetes Care. 2005; 28:398-403.

[5] Chobanian AV, Bakris GL, Black HR, Cushman WC, Green LA, Izzo JL, Jr, Jones DW, Materson BJ, Oparil S, Wright JT, Jr, Roccella EJ.: The Seventh Report of the Joint National Committee on Prevention, Detection, Evaluation, and Treatment of High Blood Pressure: the JNC 7 report. JAMA 2003; 289: 2560- 2572

[6] Richard E Pratley, Glenn Matfin, Pre-Diabetes: Clinical Relevance and Therapeutic Approach, British Journal of Diabetes and Vascular Disease. 2007;7(3):120-129. 